\title{
Potassium Deposition During And After Hypokinesia In Potassium Supplemented And Unsupplemented Rats
}

\author{
Yan G. Zorbas ${ }^{1}$, Kostas K. Kakuris², Kyrill P. Charapakhin ${ }^{1}$ and Andreas B. Afoninos ${ }^{2}$ \\ 1 Higher Institute of Biochemistry, Gomel, Belarus \\ 2 European Foundation of Environmental Sciences, Athens, Greece \\ Corresponding address: Dr. Kostas K. Kakuris, European Foundation of Environmental Sciences, Odos Kerasundos 2, GR-162 32 \\ Athens, Greece
}

Received: 2004.12.23; Accepted: 2005.05.27; Published: 2005.07.01

The aim of this study was to determine that hypokinesia (restricted motor activity) could increase potassium $\left(\mathrm{K}^{+}\right)$losses with decreased tissue $\mathrm{K}^{+}$content showing decreased $\mathrm{K}^{+}$deposition. To this end, measurements were made of $\mathrm{K}^{+}$absorption, tissue $\mathrm{K}^{+}$content, plasma $\mathrm{K}^{+}$levels, fecal and urinary $\mathrm{K}^{+}$excretion during and after hypokinesia (HK) with and without $\mathrm{K}^{+}$supplementation.

Studies conducted on male Wistar rats during a pre-hypokinetic period, a hypokinetic period and a post-hypokinetic period. Rats were equally divided into four groups: unsupplemented vivarium control rats (UVCR), unsupplemented hypokinetic rats (UHKR), supplemented vivarium control rats (SVCR) and supplemented hypokinetic rats (SHKR). SHKR and UHKR were kept in small individual cages which restricted their movements in all directions without hindering food and water consumption. SVCR and UVCR were housed in individual cages under vivarium control conditions. SVCR and SHKR consume daily $3.96 \mathrm{mEq}$ potassium chloride $(\mathrm{KCl})$ per day.

Absorption of $\mathrm{K}^{+}$, and $\mathrm{K}^{+}$levels in bone, muscle, plasma, urine and feces and PA levels did not change in SVCR and UVCR compared with their pre-HK levels. During HK, plasma, fecal and urinary $\mathrm{K}^{+}$levels and plasma aldosterone (PA) levels increased significantly $(\mathrm{p}<0.05)$ with time, while $\mathrm{K}^{+}$absorption, muscle and bone $\mathrm{K}^{+}$content decreased significantly $(p<0.05)$ with time in SHKR and UHKR compared with their pre-HK values and the values in their respective vivarium controls (SVCR and UVCR). During the initial 9-days of post-HK, $\mathrm{K}^{+}$absorption increased significantly $(\mathrm{p}<0.05)$ and plasma $\mathrm{K}^{+}$levels, fecal and urinary $\mathrm{K}^{+}$losses and PA levels decreased significantly $(\mathrm{p}<0.05)$ and muscle and bone $\mathrm{K}^{+}$content remained significantly $(\mathrm{p}<0.05)$ depressed in SHKR and UHKR compared with their pre-HK and their respective vivarium control values. During $\mathrm{HK}$ and post-HK periods, $\mathrm{K}^{+}$absorption, bone and muscle $\mathrm{K}^{+}$content, and $\mathrm{K}^{+}$levels in plasma, urine and feces and PA levels were affected significantly $(\mathrm{p}<0.05)$ more in SHKR than in UHKR. By the 15th day of post-HK the values in SHKR and UHKR approach the control values.

The higher $\mathrm{K}^{+}$losses during $\mathrm{HK}$ with decreased tissue $\mathrm{K}^{+}$levels shows decreased $\mathrm{K}^{+}$deposition. The higher $\mathrm{K}^{+}$loss with lower tissue $\mathrm{K}^{+}$levels in SHKR than in UHKR shows that $\mathrm{K}^{+}$deposition decreases more with $\mathrm{K}^{+}$supplementation than without. Because SHKR had shown lower tissue $\mathrm{K}^{+}$content and lost higher $\mathrm{K}^{+}$amounts than UHKR it was concluded that the risk of decreased $\mathrm{K}^{+}$deposition and tissue $\mathrm{K}^{+}$depletion is inversely related to $\mathrm{K}^{+}$intake, i.e., the higher $\mathrm{K}^{+}$ intake, the greater the risk for decreased $\mathrm{K}^{+}$deposition, and the higher $\mathrm{K}^{+}$losses and the greater the risk for tissue $\mathrm{K}^{+}$ depletion. The dissociation between tissue $\mathrm{K}^{+}$depletion and $\mathrm{K}^{+}$excretion indicates decreased $\mathrm{K}^{+}$deposition as the principal mechanism of tissue $\mathrm{K}^{+}$depletion during prolonged $\mathrm{HK}$.

K ey words: tissue potassium depletion, potassium absorption, potassium supplementation, hypokinesia, sedentary conditions, nutrition.

\section{Introduction}

Muscular activity is regarded as an important factor in normal regulation of electrolyte deposition in animals and humans. The mechanism by which motor activity affects electrolyte deposition is not known, but in its absence, such as during hypokinesia (restricted motor activity) the result is electrolyte loss with electrolyte imbalance. Consequently, any condition which contributes to the decreased level of motor activity bound to affect electrolyte deposition in animals and humans and thus electrolyte losses from the body in the presence of electrolyte imbalance.

Studies on animals have already documented the role of prolonged HK in the genesis of impaired ability of the body to deposit electrolytes [1-3]. The decreased electrolyte deposition during $\mathrm{HK}$ is characterized by the increase of electrolyte losses in the presence of decrease of tissue electrolyte content [1-3]. It is remarkable; however, that few studies have been carried out on the effect of HK on electrolyte deposition, either in animals or humans, although animals are subjected to prolonged HK because of several reasons and the human population is increasingly subjected to prolonged HK because of age, disease, disability, sedentary living and working conditions. In fact, few studies have been published on the effect of prolonged HK on electrolyte excretion in animals with electrolyte depletion [1-6], and there no additional literature-based information was retrieved from different medical data bases. During prolonged HK electrolyte deposition was shown to be decreased more with electrolyte supplementation than without [1-3]. Moreover, electrolyte loss increases as the duration of the HK period increased, demonstrating that the effect of $\mathrm{HK}$ and/or duration of HK is crucial for the decreased electrolyte deposition and thus for electrolyte loss from the body and the development of tissue electrolyte depletion [1-3].

The coefficient of distribution of electrolytes in tissue and plasma, and between tissue and plasma is the integral 
characteristic of the functional state of skeletal muscles. Being involved in the finely regulated processes of active membrane transport and intracellular phases, electrolytes are distributed in muscles according to the functional condition of the system of membranomyo-fibril conjugation [7], levels of metabolic activity of cell [8], and chemical condition of the cytoplasmic template that carries fixed charges [9]. Thus, any condition that is affecting motor activity, would inevitably contribute to redistribution of electrolytes in the body resulting to changes in tissue electrolyte content [1-3] and plasma electrolyte levels [4-6]. The impact of HK on electrolyte content in bone and muscle, plasma electrolyte levels and electrolyte excretion deserves special attention in determining the mechanisms of decreased electrolytes deposition.

Although the mechanisms of decreased electrolyte deposition have not yet been established, it is known that decreased tissue electrolyte content [1-3] is susceptible to increased electrolyte losses [4-6] showing decreased electrolyte deposition. However, little it is known about the reasons of decreased $\mathrm{K}^{+}$deposition with tissue $\mathrm{K}^{+}$ depletion and it is still unknown by what mechanisms HK could contribute to the decreased $\mathrm{K}^{+}$deposition and subsequently to the increase of $\mathrm{K}^{+}$loss with tissue $\mathrm{K}^{+}$ depletion. To this end few studies have been made of the effect of $\mathrm{HK}$ on $\mathrm{K}^{+}$deposition [10-12]. Measuring tissue $\mathrm{K}^{+}$ content, plasma $\mathrm{K}^{+}$levels and $\mathrm{K}^{+}$excretion during $\mathrm{HK}$ and post-HK is important to determine the mechanisms for decreased $\mathrm{K}^{+}$deposition with tissue $\mathrm{K}^{+}$depletion.

The aim of this study was to show that HK could increase $\mathrm{K}^{+}$loss with decreased tissue $\mathrm{K}^{+}$level showing decreased $\mathrm{K}^{+}$deposition. Measurements of $\mathrm{K}^{+}$absorption, tissue $\mathrm{K}^{+}$level and $\mathrm{K}^{+}$levels in plasma, urine and feces during $\mathrm{HK}$ and post-HK with and without $\mathrm{K}^{+}$ supplements were made.

\section{Materials and Methods}

Four hundred eight 13-week-old Wistar male rats were obtained from a Local Animal Research Laboratory. On arrival they were given an adaptational dietary period of 9-days during which they were fed a commercial laboratory diet. At the start of the study, all rats were about 90 -days old and weighted 375 to 395 g. All rats were housed in individual metabolic cages where light (07:00 to $19: 00 \mathrm{~h})$, temperature $\left(25 \pm 1^{\circ} \mathrm{C}\right)$ and relative humidity $(65 \%)$ was automatically controlled. Cages were cleaned daily in the morning before feeding. The studies were approved by the Committee for the Protection of Animals.

Assignment of animals into four groups was performed randomly and their conditions were:

Group one: one hundred-two unrestrained rats were housed in individual cages for 98-days under vivarium control conditions without $\mathrm{K}^{+}$supplementation. They served as unsupplemented vivarium control rats (UVCR).

Group two: one hundred-two restrained rats were kept in small individual cages for 98-days under HK without $\mathrm{K}^{+}$supplementation. They served as unsupplemented hypokinetic rats (UHKR).

Group three: one hundred-two unrestrained rats were housed in individual cages for 98-days under vivarium control conditions. They were supplemented with $\mathrm{K}^{+}$and served as supplemented vivarium control rats (SVCR).
Group four: one hundred-two restrained rats were kept in small individual cages for 98-days under HK. They were supplemented with $\mathrm{K}^{+}$and served as supplemented hypokinetic rats (SHKR).

\section{Protocol}

Hypokinetic studies were preceded by a pre-HK period of 9-days that involved a series of biochemical examinations, training, testing and conditioning of animals to their laboratory conditions. The preparation period carried out for collecting baseline values about bone and muscle content, $\mathrm{K}^{+}$absorption, PA, plasma, urine and fecal $\mathrm{K}^{+}$values. This adaptation period aimed at minimizing hypokinetic stress due to diminished motor activity $[13,14]$.

\section{Simulation of hypokinesia}

Hypokinetic rats were kept for 98-days in small individual wooden cages. Cages dimensions of $195 \times 80 \times$ 95 allowed movements to be restricted in all directions without hindering food and water consumption. All hypokinetic rats could still assume a natural position that allowed them to groom different parts of their body. When necessary, the conditions of the individual cages could be change using special wood inserts. The cages were constructed in such a way that their size could be changed in accordance with the size of each rat, so that the degree of restriction of motor activity could be maintained at a relatively constant level throughout the HK period.

\section{Food and water consumption}

A daily food consumption was measured and $90 \%$ of a daily consumption (12 g) was mixed with deionized distilled water (1:2 wt/vol) to form a slurry which was divided into two meals. All rats were pair-fed and daily food consumption was measured during pre-HK period, HK period and post-HK period. Control rats were allowed to eat approximately the same amount of food as the hypokinetic rats. Food was placed daily in individual feeders formed by the little trough and wood partitions. Food was from the same production lots that contained all essential nutrients: $19 \%$ protein, $4 \%$ fat, $38 \%$ carbohydrates, $16 \%$ cellulose, vitamins, A, D, E, $0.5 \%$ sodium chloride, $0.9 \%$ calcium, $0.8 \%$ phosphorus, $0.5 \%$ magnesium and $0.49 \%$ potassium per one g diet and kept in a cold chamber $\left(-4{ }^{0} \mathrm{C}\right)$. Food consumption was measured daily by weighing (Mettler PL 200 top loading balance) the slurry food containers. All rats receive daily deionized-distilled water ad libitum. Water dispensers (120 to $150 \mathrm{~mL}$ ) were secured onto a wooden plate installed on the front cage panels and filled daily. Rats were weighed daily between 9 and 10 a.m.

\section{Potassium consumption and potassium absorption measurements}

Supplemented rats consumed daily $3.96 \mathrm{mEq}$ potassium chloride $(\mathrm{KCl})$ before, during and after HK. This $\mathrm{K}^{+}$amount was designed to facilitate the maximal absorption of $\mathrm{K}^{+}$supplementation by remaining just below the renal tubular maximum for $\mathrm{K}^{+}$absorption [15]. To minimize diurnal variations, plasma samples for each rat were drawn at identical times of the day and after $\mathrm{K}^{+}$ was consumed. The $\mathrm{K}^{+}$amount in the diet was calculated directly by keeping an exact duplicate of the consumed food of each rat and the total $\mathrm{K}^{+}$loss in $24 \mathrm{~h}$ urine and fecal samples were measured. Measuring $\mathrm{K}^{+}$absorption [(intake-losses)/intake], with and without 
$\mathrm{K}^{+}$supplementation, required the consumption of a calculated potassium amount, followed by $24 \mathrm{~h}$ urine and fecal collection, with calculation of the percentage of $\mathrm{K}^{+}$ retained in the body. That is, absorption of $\mathrm{K}^{+}$is equal to [(intake- excretion in urine and feces)/intake] and expressed as percent on a per day basis. The potassium amounts in the $24 \mathrm{~h}$ urine and fecal collections during the pre-HK period were considered to be each rat's pre-HK values of urine and fecal excretion. These potassium values were then subtracted from $\mathrm{K}^{+}$in the $24 \mathrm{~h}$ urine and fecal collections during $\mathrm{HK}$ and post-HK and after potassium consumption. The differences were compared with the total amount of potassium consumed and then expressed as a percentage of $\mathrm{K}^{+}$absorption $24 \mathrm{~h}$ after $\mathrm{K}^{+}$ consumption.

\section{Plasma, urine and fecal sample collection}

Urine and feces were collected from each rat every day and pooled to form 6-days composites, while plasma samples were collected every 6-days during pre-HK, HK and post-HK. A 6-day (consecutive day) pooled data were collected. Blood sample were collected with disposable polypropylene syringes. Blood samples of 1.5-2.5 mL were obtained via a cardiac puncture from ether-anaesthetized rats. To obtain plasma, blood samples were transferred into polypropylene tubes containing sodium heparin. Samples were centrifuged immediately at $10,000 \times \mathrm{g}$ for 3 min at room temperature and separated using glass capillary pipets which had been washed in hydrochloric acid and deionized water. Aliquots for plasma potassium $\left(\mathrm{K}^{+}\right)$and plasma aldosterone (PA) analysis kept frozen at $-20{ }^{\circ} \mathrm{C}$. A stainless steel urine-feces separating funnels (Hoeltge, model HB/SS) was placed beneath each rat to collect uncontaminated $24 \mathrm{~h}$ urine samples. Twenty-fourhour urine samples uncontaminated by stools obtained. To ensure $24 \mathrm{hr}$ urine collections creatinine excretion was measured. Urine was collected in a beaker with layer of electrolytes oil to prevent evaporation. Beakers were replaced daily. Urine for each $24 \mathrm{~h}$ period was collected in acidified acid-wash containers and refrigerated at $-4{ }^{\circ} \mathrm{C}$ until needed for $\mathrm{K}^{+}$analysis. Fecal samples were collected in plastic bags, dried, wet ashed with acid, diluted as necessary and analyzed for $\mathrm{K}^{+}$levels. To ensure a complete recovery of feces a marker was used.

\section{Muscle and bone sample collection}

Six hypokinetic and control rats from each group were sacrificed by decapitation on the 1st, 5 th and 9 th day of the pre-HK period, on the 3rd, 7th, 15th, 30th, 50th, 70th and 98th of $\mathrm{HK}$ and on the 1st, 3rd, 5th 7th, 9th, 11th and 15th day of post-HK. Muscle (gastrocnemius) and bone (right femur) data are given in average of 6-rats. Bones were cleaned of soft tissues, dried to a constant weight, weighed, reduced to ash in a muffle furnace at 600 degrees for 144 minute, then ash was weighed and dissolved in $0.05 \mathrm{~N} \mathrm{HCl}$ and, as a chloride solution, analyzed for $\mathrm{K}^{+}$. Muscles were excised immediately after sacrificing the rats. Muscles were thoroughly cleaned of connective tissues, fatty inclusions and large vessels, weighed on Teflon liners and placed in a drying chamber at $110{ }^{\circ} \mathrm{C}$. After drying to a constant weight tissue transferred to quartz tubes for mineralization by means of concentrated $\mathrm{HNO}_{3}$, distilled off in a quartz apparatus. After ashing, the residue was dissolved in $0.05 \mathrm{M} \mathrm{HCl}$ and, as chloride solution, analyzed for $\mathrm{K}^{+}$content.

Potassium and aldosterone measurements
All samples were analyzed in duplicate, and appropriate standards were used for measurements: The $\mathrm{K}^{+}$content in muscle (gastrocnemius) and bone (right femur), and $\mathrm{K}^{+}$levels in plasma, feces and urine were measured by atomic absorption spectrophotometry on a Perkin-Elmer 420 Model (Perkin-Elmer Corp., Norwalk. CT). Plasma aldosterone concentration was measured using radioimmunoassay test kits (Diagnostics Products Corp., Los Angeles, CA).

\section{Statistical analyses}

Results were analyzed with a 2-way ANOVA(hypokinetic vs. active controls)
(supplemented versus unsupplemented) X 2 intervention vs. post-intervention) with repeated measures on the last factor. The Tukey-Kramer correction for multiple comparisons was used. A format analysis was conducted to establish the shape of changes. A correlation coefficient was used to show the relationship between $\mathrm{K}^{+}$ absorption and $\mathrm{K}^{+}$levels in tissue, plasma, feces and urine. Predetermined level of significance was set at alpha $<0.05$. The data were reported as mean $\pm S D$.

\section{Results}

\section{Pre-hypokinetic potassium values with and without potassium supplementation}

Potassium absorption, PA levels, and $\mathrm{K}^{+}$levels in muscle, bone, plasma, feces and urine were not different between hypokinetic and control rats during pre-HK (Table 1). No differences were observed between supplemented and unsupplemented control and hypokinetic rats regarding PA levels, $\mathrm{K}^{+}$absorption, and $\mathrm{K}^{+}$levels in muscle, bone, plasma, urine and feces (Table 1).

\section{Hypokinetic potassium values with and without potassium supplementation}

Potassium absorption, muscle and bone $\mathrm{K}^{+}$content, $\mathrm{K}^{+}$levels in plasma, urine and feces and PA levels did not change in UVCR and SVCR compared with their pre-HK values (Table 1).During $\mathrm{HK}, \mathrm{K}^{+}$absorption, muscle and bone $\mathrm{K}^{+}$content decreased significantly $(\mathrm{p}<0.05)$ with time, and PA levels, plasma, fecal and urinary $\mathrm{K}^{+}$levels increased significantly $(\mathrm{p}<0.05)$ with time in UHKR and SHKR compared with their pre-HK values and the values in their respective vivarium controls (UVCR and SVCR) (Table 1). However, $\mathrm{K}^{+}$absorption, muscle and bone $\mathrm{K}^{+}$ content decreased significantly $(\mathrm{p}<0.05)$ more with time, and PA levels, and $\mathrm{K}^{+}$levels in plasma, feces and urine increased significantly $(\mathrm{p}<0.05)$ more with time in SHKR than in UHKR (Table 1). A significant correlation $r=0.93$ was present between decreased $\mathrm{K}^{+}$absorption, lower tissue $\mathrm{K}^{+}$levels, and higher $\mathrm{K}^{+}$levels in plasma, urine and feces. Although, $\mathrm{K}^{+}$absorption, muscle and bone $\mathrm{K}^{+}$ content, PA concentration, and $\mathrm{K}^{+}$levels in plasma, urine and feces were fluctuated throughout the HK period they never reverted back to the control values (Table 1).

\section{Post-hypokinetic potassium values with and without potassium supplementation}

Potassium absorption, muscle and bone $\mathrm{K}^{+}$content, PA level, plasma, urine and fecal $\mathrm{K}^{+}$levels did not change in UVCR and SVCR compared with their pre-HK values (Table 2). During the initial 9-days of post-HK, $\mathrm{K}^{+}$ absorption increased significantly $(\mathrm{p}<0.05)$ and PA levels, plasma, fecal and urinary $\mathrm{K}^{+}$levels decreased significantly 
$(\mathrm{p}<0.05)$, while muscle and bone $\mathrm{K}^{+}$content remained significantly $(p<0.05)$ depressed in UHKR and SHKR compared with their respective vivarium controls (UVCR and SHKR) (Table 2). However, $\mathrm{K}^{+}$absorption increased significantly $(\mathrm{p}<0.05)$ more, and PA levels, plasma $\mathrm{K}^{+}$ levels, urine and fecal $\mathrm{K}^{+}$excretion decreased significantly $(\mathrm{p}<0.05)$ more, while muscle and bone $\mathrm{K}^{+}$content remained significantly $(p<0.05)$ more depressed in SHKR than in UHKR (Table 2). A significant correlation $r=0.93$ was present between increased $\mathrm{K}^{+}$absorption, and decreased $\mathrm{K}^{+}$levels in tissue, plasma, urine and feces. Although $\mathrm{K}^{+}$absorption, muscle and bone $\mathrm{K}^{+}$levels, PA level, plasma, urine and fecal $\mathrm{K}^{+}$level fluctuated throughout post-HK, these values approached the control values only by the 15th day.

\section{Discussion}

\section{Pre-hypokinetic plasma potassium with and without potassium supplementation}

During pre-HK, plasma $\mathrm{K}^{+}$levels in hypokinetic and control rats did not alter with potassium supplementation or without. This shows that $\mathrm{K}^{+}$deposition was stable in hypokinetic and control rats). Stable plasma $\mathrm{K}^{+}$level during normal motor activity shows that $\mathrm{K}^{+}$is readily bound to muscle, which means that $\mathrm{K}^{+}$is deposited in muscle [1-3].This is because the ingested $\mathrm{K}^{+}$amount is retained by the body and is taken up for deposition in muscle [1-3]. The pre-HK values likely reflect conditions where $\mathrm{K}^{+}$is retained and is taken up for deposition in muscle than shown up in plasma. Concluding therefore that $\mathrm{K}^{+}$deposition was remained stable during pre-HK is justified.

\section{Plasma aldosterone changes during hypokinesia with and without potassium supplementation}

PA levels increased significantly during HK, even in the face of the decrease of tissue $\mathrm{K}^{+}$content. The PA levels increased more with $\mathrm{K}^{+}$supplementation than without. Supplementation of $\mathrm{K}^{+}$did not result in analogous changes in SVCR showing that the increase of PA levels is important. Tissue $\mathrm{K}^{+}$depletion during $\mathrm{HK}$ is probably not associated with increase of PA levels. This is because, the increase of PA levels and tissue $\mathrm{K}^{+}$depletion did not show any form of relationship. Increased PA levels could not explain the increase of $\mathrm{K}^{+}$excretion with tissue $\mathrm{K}^{+}$ depletion. Increase of plasma $\mathrm{K}^{+}$levels and $\mathrm{Na}^{+}$losses during HK is quite surprising in that increase of PA levels should have led to an antinatriuretic and kaliuretic effect, respectively [15]. The increase of PA levels during HK is also quite surprising in that this is usually associated with a reduction in activity of sympathetic nervous system that, in turn, contributes to decreased PA levels [15]. This may provide hints of severe body dehydration and decreased extracellular fluid volume that could have intensified the effect of $\mathrm{HK}$ on $\mathrm{K}^{+}$deposition [15]. The increased plasma $\mathrm{K}^{+}$concentration and increased urinary $\mathrm{K}^{+}$loss could point towards a change in the tubular response to aldosterone during HK. Because a higher $\mathrm{K}^{+}$intake is associated with greater tissue $\mathrm{K}^{+}$loss this could have had a direct effect on the decreased plasma aldosterone concentration during prolonged $\mathrm{HK}$.

\section{Tissue potassium with and without potassium supplementation during hypokinesia}

During normal motor activity, $\mathrm{K}^{+}$intake in large amounts usually contributes to over absorption and uptake of $\mathrm{K}^{+}$, while during $\mathrm{HK}$ no matter if animals or humans ingest $\mathrm{K}^{+}$in large or small amounts, $\mathrm{K}^{+}$absorption and uptake is depressed [10-12]. The $\mathrm{K}^{+}$depletion during normal motor activity is accompanied by an increase of $\mathrm{K}^{+}$ absorption and uptake,however, $\mathrm{K}^{+}$depletion during HK, is associated with a decrease of $\mathrm{K}^{+}$absorption and uptake [10-12]. During pre-HK, $\mathrm{K}^{+}$intake was deposited to a great extent in bone and muscle that protects plasma $\mathrm{K}^{+}$from any increase.

The most striking abnormality shown during $\mathrm{HK}$ is the increased $\mathrm{K}^{+}$loss in the face of tissue $\mathrm{K}^{+}$depletion. Hypokinetic rats have shown significant decrease of $\mathrm{K}^{+}$ level in bone and muscle with different functional activity and morphological characteristics. Generally electrolytes are reduced most in muscle and bone that have a support function [16].The severity of decreased muscle and bone $\mathrm{K}^{+}$level was different in gastrocnemius muscle and right femur that have different function and morphology; $\mathrm{K}^{+}$ content decreased mostly in gastrocnemius muscle and least in right femur. The mechanism by which $\mathrm{K}^{+}$level decreased in bone and muscle with different morphology and function is not clear, while there are grounds to conclude that increased tissue electrolyte loss is attributable to several factors [1-3, 16]. Decreased tissue electrolyte level is primarily attributable to increased electrolyte loss with tissue electrolyte depletion [1-3, 16]; this is possibly ensured by decreased tissue electrolyte deposition due to decreased cell mass [16]. Thus, decreased tissue $\mathrm{K}^{+}$content is attributable to higher $\mathrm{K}^{+}$ losses due to the decreased bone and muscle $\mathrm{K}^{+}$ deposition regardless their morphology and function. The magnitude of increased tissue $\mathrm{K}^{+}$loss shows the intensity of diminished motor activity and decreased mechanical load in the right femur and gastrocnemius muscle and thus intensity of decreased $\mathrm{K}^{+}$deposition $[1-3,16]$. The mechanism by which the higher $\mathrm{K}^{+}$intake is associated with greater tissue $\mathrm{K}^{+}$loss during $\mathrm{HK}$ remains unclear.

The increased $\mathrm{K}^{+}$losses with tissue $\mathrm{K}^{+}$depletion definitely had show impossibility of the body to deposit $\mathrm{K}^{+}$. Measuring $\mathrm{K}^{+}$absorption, it was shown that the higher $\mathrm{K}^{+}$losses with lower tissue $\mathrm{K}^{+}$content, the lower $\mathrm{K}^{+}$ deposition. This shows that the decreased muscle and bone $\mathrm{K}^{+}$content is accompanied by an increase of $\mathrm{K}^{+}$loss. The increased electrolyte losses in the face of decreased bone and muscle electrolyte levels have been shown to be attributable to the decreased electrolyte deposition [1-3]. The fact that the increase of electrolyte losses with tissue electrolyte depletion reflects decreased electrolyte deposition has been known for many years [15, 16]; however, it has been rarely applied because of the difficulties for measuring electrolyte deposition. Meanwhile, evidence is emerging to indicate that the decreased electrolyte deposition is attributable to several factors and primarily to the decreased cell mass [16]. The mechanism of decreased $\mathrm{K}^{+}$absorption and thus increased $\mathrm{K}^{+}$losses with decreased tissue $\mathrm{K}^{+}$levels remain unclear and require further studies. The mechanism for decreased $\mathrm{K}^{+}$absorption during $\mathrm{HK}$ might be established by studying the factors contributing to decreased $\mathrm{K}^{+}$ deposition and in particular to that of muscle cell mass.

With tissue $\mathrm{K}^{+}$depletion higher $\mathrm{K}^{+}$loss was significantly greater in SHKR than in UHKR. Higher $\mathrm{K}^{+}$ losses with $\mathrm{K}^{+}$supplementation than without and tissue $\mathrm{K}^{+}$depletion definitely shows lower $\mathrm{K}^{+}$deposition in SHKR than in UHKR. The lower tissue $\mathrm{K}^{+}$level in SHKR than in UHKR shows that tissue $\mathrm{K}^{+}$could not reach any 
degree of normalcy with $\mathrm{K}^{+}$supplementation. Higher $\mathrm{K}^{+}$ intake with lower tissue $\mathrm{K}^{+}$level led to higher $\mathrm{K}^{+}$loss compared with lower $\mathrm{K}^{+}$intake and lower tissue $\mathrm{K}^{+}$ content. This resembles a vicious circle, that is, the higher $\mathrm{K}^{+}$intake, the lower $\mathrm{K}^{+}$absorption, the higher $\mathrm{K}^{+}$losses and the greater tissue $\mathrm{K}^{+}$depletion. Tissue $\mathrm{K}^{+}$depletion as a percentage of $\mathrm{K}^{+}$intake was the consequence of decreased $\mathrm{K}^{+}$absorption. Because SHKR experienced higher $\mathrm{K}^{+}$losses with lower tissue $\mathrm{K}^{+}$content than UHKR it was shown that the more $\mathrm{K}^{+}$is consumed the more efficiently $\mathrm{K}^{+}$is cleared from the blood stream and the more readily $\mathrm{K}^{+}$is lost, and the less likely it is to normalize tissue $\mathrm{K}^{+}$depletion. It is unknown for what reasons SHKR with lower tissue $\mathrm{K}^{+}$level would have shown greater $\mathrm{K}^{+}$losses than UHKR. It has been shown [10-12] that the higher $\mathrm{K}^{+}$intake, the higher $\mathrm{K}^{+}$losses with $\mathrm{K}^{+}$imbalance. The higher $\mathrm{K}^{+}$intake is increasingly been recognized as an important determinant of higher $\mathrm{K}^{+}$ losses with $\mathrm{K}^{+}$imbalance [10-12, 15]. Moreover, a higher $\mathrm{K}^{+}$intake may places a severe stress on the body leading to the decreased $\mathrm{K}^{+}$absorption and higher $\mathrm{K}^{+}$losses [10$12,15]$. The higher $\mathrm{K}^{+}$loss with tissue $\mathrm{K}^{+}$depletion is more likely to be attributable to a more degraded $\mathrm{K}^{+}$deposition with $\mathrm{K}^{+}$supplementation than without.

\section{Tissue potassium with and without potassium supplementation during post-hypokinesia}

The decrease of $\mathrm{K}^{+}$excretion during post-HK shows tissue $\mathrm{K}^{+}$depletion because it is known that decreased electrolyte excretion occurs with tissue electrolyte depletion unless other overriding factors coexist. Assuming that rats had not experienced tissue $\mathrm{K}^{+}$ depletion then they could not have shown any decrease of $\mathrm{K}^{+}$excretion during post-HK. Thus, decreased $\mathrm{K}^{+}$ excretion during post- $\mathrm{HK}$ is attributable to the tissue $\mathrm{K}^{+}$ depletion, while the results obtained provided convicting evidence of the role of $\mathrm{HK}$ in the genesis of tissue $\mathrm{K}^{+}$ depletion. Measuring $\mathrm{K}^{+}$absorption it was shown that the lower $\mathrm{K}^{+}$excretion, the greater tissue $\mathrm{K}^{+}$depletion. The continuing decrease of $\mathrm{K}^{+}$excretion during post-HK could have been attributable to the magnitude of tissue $\mathrm{K}^{+}$ depletion. Decreased electrolyte excretion develops in response to the tissue electrolyte depletion and/or increased motor activity [1-3]. Decreased $\mathrm{K}^{+}$excretion during initial 3-days of post-HK could have been directed towards normalizing tissue $\mathrm{K}^{+}$depletion, while decreased $\mathrm{K}^{+}$excretion during the subsequent days could have resulted from the resumption of motor activity. Because tissue $\mathrm{K}^{+}$content normalized at the end post-HK it was concluded that tissue $\mathrm{K}^{+}$depletion recovers only when motor activity is restored. When tissue $\mathrm{K}^{+}$level increased as the duration of post-HK period increased, $\mathrm{K}^{+}$excretion increased and by the end of post-HK approached the control values.

The decreased $\mathrm{K}^{+}$excretion at the initial stages of post-HK shows that tissue $\mathrm{K}^{+}$level could not reach any degree of normalcy with $\mathrm{K}^{+}$supplementation. The magnitude of decreased $\mathrm{K}^{+}$excretion during post-HK and $\mathrm{K}^{+}$supplementation shows the magnitude of tissue $\mathrm{K}^{+}$ depletion during $\mathrm{HK}$, and that the body could not react to the daily $\mathrm{K}^{+}$supplementation due to the intensity of tissue $\mathrm{K}^{+}$depletion. Because $\mathrm{K}^{+}$supplementation failed to affect tissue $\mathrm{K}^{+}$depletion at the initial stages of post-HK, and tissue was repleted with $\mathrm{K}^{+}$at the end of post-HK period, it was shown that tissue $\mathrm{K}^{+}$depletion cannot be normalized with $\mathrm{K}^{+}$supplementation unless $\mathrm{K}^{+}$deposition and motor activity are restore. In favor of this are many facts available, for instance, $\mathrm{K}^{+}$supplementation did not normalize tissue $\mathrm{K}^{+}$content until $\mathrm{K}^{+}$deposition and motor activity were restored. Decrease of $\mathrm{K}^{+}$excretion during post-HK and $\mathrm{K}^{+}$supplementation could have been attributable to tissue $\mathrm{K}^{+}$depletion, because decrease of electrolyte excretion is associated with electrolyte depletion $[1-3,16]$. Thus, decreased $\mathrm{K}^{+}$excretion during post-HK and $\mathrm{K}^{+}$supplementation is attributable to the decrease of tissue $\mathrm{K}^{+}$content. However, because of the presence many factors known to affect tissue $\mathrm{K}^{+}$content, it is difficult to establish the mechanisms of tissue $\mathrm{K}^{+}$ depletion during HK.

In contrast to non-hypokinetic studies, the daily $\mathrm{K}^{+}$ supplementation did not influence tissue $\mathrm{K}^{+}$depletion during HK. Specific differences between conditions (ambulatory vs hypokinetic) and/or decreased $\mathrm{K}^{+}$ deposition could had minimize the effect of $\mathrm{K}^{+}$ supplementation on tissue $\mathrm{K}^{+}$depletion. Available data [16] have shown that decreased muscle cell mass, due to many factors, is probably the primary contributor for the decreased $\mathrm{K}^{+}$deposition. Other potential factors may be present which could have contributed to the decreased $\mathrm{K}^{+}$ deposition. Many mechanisms have been proposed to explain the impaired electrolyte deposition following electrolyte depletion with and without electrolyte supplementation [1-3, 16]. Chief among these are 1) muscle wasting, 2) decreased muscle cell mass, 2) diminished size of electrolyte pool of cell, 3) change in electrolyte content of cell and 3) injury of skeletal muscle cell that change integrity of sarcolemma and results in release of intracellular electrolytes in plasma. The decreased muscle cell mass results in decreased holding capacity for $\mathrm{K}^{+}$, contribute in this phase of development of this condition to the decreased $\mathrm{K}^{+}$deposition. Thus, $\mathrm{K}^{+}$ supplementation would fail to correct the normalcy of $\mathrm{K}^{+}$ deposition in animals and humans, and in critical ill patients and in people forced to decrease their muscular activity for various reasons, allowing muscle cell mass to shrink further. Thus, the biological mechanisms and potential effect of decreased muscle cell mass on the decreased $\mathrm{K}^{+}$deposition during prolonged $\mathrm{HK}$ may be found at the cell level.

\section{Conclusion}

The increase of $\mathrm{K}^{+}$loss with decrease of tissue $\mathrm{K}^{+}$ content demonstrates decreased $\mathrm{K}^{+}$deposition. Higher $\mathrm{K}^{+}$ losses with lower tissue $\mathrm{K}^{+}$content in SHKR than in UHKR shows that $\mathrm{K}^{+}$deposition is decreased more with than without $\mathrm{K}^{+}$supplementation. Because SHKR with a lower tissue $\mathrm{K}^{+}$content shows higher $\mathrm{K}^{+}$loss than UHKR it is indicated that the risk of decreased $\mathrm{K}^{+}$deposition with greater tissue $\mathrm{K}^{+}$depletion is inversely related to $\mathrm{K}^{+}$ intake, that is, the higher $\mathrm{K}^{+}$intake, the greater the risk for the decreased $\mathrm{K}^{+}$deposition, the higher $\mathrm{K}^{+}$losses and the greater tissue $\mathrm{K}^{+}$depletion. It was shown that $\mathrm{K}^{+}$, regardless the magnitude of its depletion, is lost during $\mathrm{HK}$ unless factors leading to decreased $\mathrm{K}^{+}$deposition are partially or totally reversed as was shown in this study. It was concluded that dissociation between decreased tissue $\mathrm{K}^{+}$levels and increased $\mathrm{K}^{+}$loss indicates decreased $\mathrm{K}^{+}$ deposition as the mechanism of tissue $\mathrm{K}^{+}$depletion during HK.

\section{Conflict of interest}

None declared. 


\section{References}

1. Zorbas YG, Verentsov GE, Bobylev VR, Yaroshenko YN, and Federenko YF. Electrolyte metabolic changes in rats during and after exposure to hypokinesia. Physiol Chem Phys Med NMR 1996; 28: 267-277.

2. Zorbas YG, Ivanov AL, and Federenko YF. Electrolyte and water content in organs and tissues of rats during and after exposure to prolonged restriction of motor activity. Rev Esp Fisiol. 1995; 51: 155162.

3. Zorbas YG, Kakurin VJ, Afonin VB, Denogradov SD and Neofitov AC. Muscle electrolyte measurements during and after hypokinesia in determining muscle electrolyte depletion during hypokinesia in rat. Biological Trace Element Research 2002; 90: 155-174.

4. Zorbas YG, Andreyev VG, and Verentsov GE. Ion regulating functions of rat kidney after hypokinesia and physical exercise. Urologia 1987; 36: 465-476.

5. Zorbas YG, and Verentsov GE. Glomerules and juxta glomerular system's structural changes in rats under hypokinesia. Materia Medica Polona 1985; 18: 228-231.

6. Zorbas YG, Federenko YF, and Naexu KA. Renal excretion of magnesium in rats subjected to prolonged restriction of motor activity and magnesium supplementation. Magnesium-Bulletin 1994; 16: 64-70.

7. Katz B. Nerves, Muscles and Synapses. Moscow: Meditsina Press, 1968.

8. Dee E, and Kerman RP. Energetics of sodium transport in ram puppies. J Physiol 1963; 165: 550-558.

9. Ling GN. Debunking the alleged resurrection of the sodium pump hypothesis. Physiol Chem Med NMR 1997; 29: 123-198.

10. Zorbas YG, Abratov NI, and Stoikolescu CB. Renal excretion of potassium in men under hypokinesia and physical exercise with

\section{Tables}

Table 1. Potassium Absorption (\%/days), Plasma (mEq/L), Urine (mEq/day), Fecal (mEq/day) Muscle (mEq/kg dry tissue) and Bone (mg/100 g ash) Potassium and Plasma Aldosterone $(\mathrm{pg} / \mathrm{mL})$ Measured in Rats at Pre-hypokinesia, and During Vivarium Control, and Hypokinesia.

All values are expressed as mean $\pm \mathrm{SD}$.

${ }^{*} \mathrm{p}<0.05$ significant differences between vivarium control and hypokinetic groups of rats. Each of the hypokinetic groups was compared with their respective vivarium controls (UVCR vs UHKR and SVCR vs SHKR).

${ }^{+} \mathrm{p}<0.05$ significant differences between supplemented and unsupplemented hypokinetic groups. chronic hyperhydration. Urologia 1988; 36: 229-238.

11. Zorbas $Y G$, Ivanov $A L$, and Immura $Y K$. Changes in total body potassium, haemoglobin and bromine space after hypokinesia and physical exercise. Materia Medica Polona 1990; 22: 300-303.

12. Zorbas YG, Yarullin VL, Denogradov SD, Afonin VB and Kakurin VJ. Potassium measurements during hypokinesia and ambulation in establishing potassium changes in trained and untrained subjects. Sports Medicine Training and Rehabilitation, 2001;10: 257-272.

13. Fedorov IV. Biochemical basis of pathogenesis of hypokinesia. Kosmicheskaya Biol. 1980; 3:3-10.

14. Zorbas YG, Verentsov GE, and Federenko YF. Renal excretion of end products of protein metabolism in urine of endurance trained subjects during restriction of muscular activity. Panminerva Med. 1995; 37:109-114.

15. Grigor'yev AI. Regulation of fluid- electrolyte metabolism and renal function in man during cosmic flights (PhD thesis). Ministry of Health USSR, Moscow, Russia: Academy of Sciences USSR and Directorate of Biology and Medicine. 1980.

16. Krotov VP. Kinetics and regulation of fluid-electrolyte metabolism in animals and man during hypokinesia (PhD thesis). Ministry of Health USSR, Moscow, Russia: Academy of Sciences USSR and Directorate of Biology and Medicine. 1981. $\begin{array}{llcc}\text { Days Absorption Plasma } \quad \text { Urine } \quad \text { Feces } & \text { Muscle, } & \text { Bone, } \\ \text { Aldosterone Gastrocnemius } & \text { Right Femur }\end{array}$

\begin{tabular}{llllllll}
\hline \multicolumn{7}{c}{ Unsupplemented Vivarium Control Rats (UVCR), $\mathrm{n}=102$} \\
Pre-HK & $60 \pm 3$ & $4.3 \pm 0.14$ & $3.21 \pm 0.35$ & $5.35 \pm 0.20$ & $46.8 \pm 5.2$ & $109.1 \pm 1.3$ & $53.3 \pm 12.2$ \\
3rd & $61 \pm 5$ & $4.2 \pm 0.15$ & $3.18 \pm 0.43$ & $5.33 \pm 0.22$ & $45.2 \pm 4.0$ & $109.5 \pm 2.2$ & $53.5 \pm 13.3$ \\
7th & $62 \pm 4$ & $4.2 \pm 0.13$ & $3.19 \pm 0.30$ & $5.30 \pm 0.27$ & $45.6 \pm 5.5$ & $109.7 \pm 1.5$ & $53.7 \pm 10.4$ \\
15th & $61 \pm 6$ & $4.1 \pm 0.14$ & $3.17 \pm 0.48$ & $5.33 \pm 0.21$ & $44.8 \pm 4.6$ & $109.5 \pm 1.5$ & $53.5 \pm 12.2$ \\
30th & $62 \pm 4$ & $4.2 \pm 0.15$ & $3.19 \pm 0.42$ & $5.32 \pm 0.25$ & $45.4 \pm 4.3$ & $109.7 \pm 1.3$ & $53.7 \pm 10.5$ \\
50th & $61 \pm 5$ & $4.2 \pm 0.13$ & $3.18 \pm 0.38$ & $5.30 \pm 0.23$ & $44.7 \pm 5.0$ & $109.9 \pm 1.4$ & $53.9 \pm 12.3$ \\
70th & $62 \pm 3$ & $4.2 \pm 0.12$ & $3.19 \pm 0.36$ & $5.31 \pm 0.26$ & $45.5 \pm 5.3$ & $109.7 \pm 1.3$ & $53.7 \pm 11.4$ \\
98th & $61 \pm 4$ & $4.3 \pm 0.14$ & $3.20 \pm 0.43$ & $5.32 \pm 0.22$ & $45.2 \pm 4.4$ & $109.8 \pm 2.2$ & $53.9 \pm 10.6$
\end{tabular}

\begin{tabular}{lccccccc}
\hline \multicolumn{7}{c}{ Unsupplemented Hypokinetic Rats (UHKR), $\mathrm{n}=102$} \\
Pre-HK 61 \pm 5 & $4.3 \pm 0.14$ & $3.20 \pm 0.41$ & $5.35 \pm 0.23$ & $45.5 \pm 4.7$ & $109.7 \pm 1.2$ & $53.2 \pm 10.5$ \\
3rd & $17 \pm 4^{*}$ & $4.8 \pm 0.16^{*}$ & $4.31 \pm 0.46^{*}$ & $7.30 \pm 0.33^{*}$ & $60.2 \pm 5.0^{*}$ & $98.4 \pm 1.4^{*}$ & $47.4 \pm 12.4^{*}$ \\
7th & $19 \pm 5^{*}$ & $4.7 \pm 0.15^{*}$ & $4.17 \pm 0.38^{*}$ & $6.87 \pm 0.40^{*}$ & $58.0 \pm 4.6^{*}$ & $99.6 \pm 1.3^{*}$ & $48.3 \pm 13.3^{*}$ \\
15th & $15 \pm 3^{*}$ & $4.9 \pm 0.15^{*}$ & $4.58 \pm 0.49^{*}$ & $8.03 \pm 0.36^{*}$ & $65.5 \pm 4.4^{*}$ & $96.1 \pm 1.4^{*}$ & $45.1 \pm 10.4^{*}$ \\
30th & $17 \pm 6^{*}$ & $4.7 \pm 0.16^{*}$ & $4.41 \pm 0.43^{*}$ & $7.61 \pm 0.43^{*}$ & $63.0 \pm 5.3^{*}$ & $98.3 \pm 1.5^{*}$ & $46.3 \pm 11.5^{*}$ \\
50th & $13 \pm 4^{*}$ & $5.0 \pm 0.15^{*}$ & $4.74 \pm 0.36^{*}$ & $8.78 \pm 0.28^{*}$ & $67.4 \pm 5.0^{*}$ & $93.0 \pm 1.4^{*}$ & $44.0 \pm 12.4^{*}$ \\
70th & $15 \pm 5^{*}$ & $4.8 \pm 0.15^{*}$ & $4.57 \pm 0.47^{*}$ & $8.27 \pm 0.35^{*}$ & $65.7 \pm 4.6^{*}$ & $95.1 \pm 1.3^{*}$ & $45.1 \pm 10.5^{*}$ \\
98th & $10 \pm 3^{*}$ & $5.1 \pm 0.14^{*}$ & $4.86 \pm 0.47^{*}$ & $9.09 \pm 0.46^{*}$ & $68.6 \pm 5.5^{*}$ & $90.2 \pm 1.5^{*}$ & $43.4 \pm 11.4^{*}$
\end{tabular}

\begin{tabular}{lrrrrrrr}
\hline \multicolumn{7}{c}{ Supplemented Vivarium Control Rats (SVCR), $\mathrm{n}=102$} \\
Pre-HK 53 \pm 5 & $4.8 \pm 0.14$ & $3.52 \pm 0.45$ & $6.11 \pm 0.41$ & $43.2 \pm 5.0$ & $113.3 \pm 1.5$ & $54.3 \pm 11.4$ \\
3rd & $53 \pm 4$ & $4.8 \pm 0.15$ & $3.57 \pm 0.41$ & $6.12 \pm 0.30$ & $41.8 \pm 4.6$ & $113.5 \pm 1.4$ & $54.5 \pm 12.5$ \\
7th & $54 \pm 3$ & $4.7 \pm 0.14$ & $3.55 \pm 0.38$ & $6.15 \pm 0.44$ & $42.6 \pm 5.5$ & $113.7 \pm 1.3$ & $54.7 \pm 10.4$ \\
15th & $53 \pm 4$ & $4.6 \pm 0.15$ & $3.57 \pm 0.44$ & $6.12 \pm 0.27$ & $41.8 \pm 5.4$ & $113.9 \pm 1.4$ & $54.9 \pm 12.3$ \\
30th & $54 \pm 5$ & $4.8 \pm 0.15$ & $3.56 \pm 0.40$ & $6.14 \pm 0.33$ & $42.6 \pm 4.7$ & $114.3 \pm 1.3$ & $55.0 \pm 10.5$ \\
50th & $53 \pm 3$ & $4.6 \pm 0.14$ & $3.53 \pm 0.35$ & $6.12 \pm 0.45$ & $41.7 \pm 5.0$ & $113.0 \pm 1.5$ & $55.1 \pm 13.4$ \\
70th & $54 \pm 4$ & $4.7 \pm 0.13$ & $3.57 \pm 0.45$ & $6.13 \pm 0.31$ & $42.5 \pm 4.5$ & $114.5 \pm 1.4$ & $54.8 \pm 10.3$ \\
98th & $53 \pm 3$ & $4.8 \pm 0.15$ & $3.56 \pm 0.37$ & $6.15 \pm 0.40$ & $41.8 \pm 4.4$ & $113.0 \pm 1.3$ & $55.0 \pm 11.5$
\end{tabular}

Supplemented Hypokinetic Rats (SHKR), $\mathrm{n}=102$

\begin{tabular}{|c|c|c|c|c|c|c|c|}
\hline L & $51 \pm 3$ & $4.7 \pm 0.15$ & $3.53 \pm 0.41$ & $6.10 \pm 0.45$ & $42.8 \pm 4.5$ & $112.5 \pm 1.3$ & \\
\hline $3 \mathrm{rd}$ & $13 \pm 4^{*^{+}}$ & $5.6 \pm 0.14^{*+}$ & $5.63 \pm 0.47^{*+}$ & $10.64 \pm 0.34^{*+}$ & $80.1 \pm 5.0^{*^{+}}$ & $87.7 \pm 1.4^{*^{+}}$ & $43.8 \pm 12.3^{*}$ \\
\hline 7th & & $5.5 \pm 0.16^{*^{+}}$ & & $10.13 \pm 0.51^{*}$ & $77.6 \pm 4.7^{*^{+}}$ & $89.3 \pm 1.5^{*^{+}}$ & $2+114$ \\
\hline 15 th & $10 \pm$ & & $5.93 \pm 0$ & $0.35^{*^{+}}$ & $85.8 \pm 5.0^{*^{+}}$ & $85.5 \pm 1.4^{*^{+}}$ & 12.5 \\
\hline Oth & $13 \pm 3 *$ & $5.7 \forall 0.15^{*}$ & $5.65 \pm 0.4$ & $0.46^{*^{+}}$ & $81.0 \pm 5.5^{*^{+}}$ & $87.3 \pm 1.2 *^{+}$ & $13.2^{*^{+}}$ \\
\hline 0 th & $07 \pm 4$ & $5.9 \pm 0$ & $6.12 \pm$ & & $87.2 \pm 4.6^{*^{+}}$ & $83.4 \pm 1.4^{*^{+}}$ & $40.8 \pm 14.3$ \\
\hline 70 th & $10 \pm 5$ & $5.8 \pm$ & $5.96 \pm$ & 12.2 & $85.5 \pm 5.0^{*^{+}}$ & $85.0 \pm 1.2^{*^{+}}$ & $42.7 \pm 10.5$ \\
\hline 8th & $07 \pm 4^{*+}$ & $6.0 \pm 0.15^{*^{+}}$ & $6.44 \pm 0.50^{*^{+}}$ & $13.00 \pm 0.38^{*+}$ & $90.2 \pm 4.7^{*^{+}}$ & $83.3 \pm 1.3^{*^{+}}$ & $40.3 \pm 12.4 *$ \\
\hline
\end{tabular}


Table 2. Potassium Absorption (\%/days), Plasma (mEq/L), Urine (mEq/day), Fecal (mEq/day) Muscle (mEq/kg dry tissue) and Bone (mg/100 g ash) Potassium and Plasma Aldosterone (pg/ mL) Measured in Rats During Vivarium Control and PostHypokinesia.

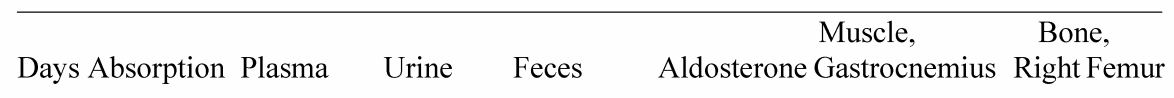

\begin{tabular}{llllllll}
\hline \multicolumn{7}{c}{ Unsupplemented Vivarium Control Rats (UVCR), $\mathrm{n}=102$} \\
2nd & $60 \pm 5$ & $4.4 \pm 0.14$ & $3.25 \pm 0.40$ & $5.37 \pm 0.32$ & $45.4 \pm 5.0$ & $109.7 \pm 1.2$ & $53.5 \pm 11.4$ \\
3rd & $61 \pm 3$ & $4.3 \pm 0.12$ & $3.23 \pm 0.36$ & $5.35 \pm 0.27$ & $46.0 \pm 4.4$ & $109.9 \pm 1.3$ & $53.7 \pm 10.5$ \\
5th & $60 \pm 4$ & $4.4 \pm 0.15$ & $3.25 \pm 0.43$ & $5.37 \pm 0.28$ & $44.5 \pm 4.0$ & $109.5 \pm 1.4$ & $53.6 \pm 12.0$ \\
7th & $61 \pm 5$ & $4.3 \pm 0.13$ & $3.23 \pm 0.35$ & $5.35 \pm 0.31$ & $45.0 \pm 5.5$ & $109.8 \pm 1.3$ & $53.8 \pm 13.3$ \\
9th & $60 \pm 4$ & $4.4 \pm 0.13$ & $3.25 \pm 0.46$ & $5.37 \pm 0.25$ & $44.7 \pm 4.3$ & $109.7 \pm 1.2$ & $53.4 \pm 10.4$ \\
11th & $61 \pm 3$ & $4.3 \pm 0.14$ & $3.24 \pm 0.38$ & $5.34 \pm 0.32$ & $45.3 \pm 5.4$ & $109.7 \pm 1.3$ & $53.6 \pm 11.0$ \\
15th & $60 \pm 5$ & $4.5 \pm 0.12$ & $3.23 \pm 0.42$ & $5.33 \pm 0.27$ & $45.8 \pm 3.6$ & $109.8 \pm 1.4$ & $53.7 \pm 10.3$
\end{tabular}

Unsupplemented Hypokinetic Rats (UHKR), n=102

$\begin{array}{llllllll}\text { 2nd } & 80 \pm 6^{*} & 3.4 \pm 0.13^{*} & 2.24 \pm 0.30^{*} & 3.47 \pm 0.40^{*} & 25.7 \pm 4.0^{*} & 90.4 \pm 1.4^{*} & 43.8 \pm 10.5^{*} \\ \text { 3rd } & 78 \pm 5^{*} & 3.5 \pm 0.12^{*} & 2.26 \pm 0.36^{*} & 3.50 \pm 0.32^{*} & 27.0 \pm 5.5^{*} & 91.0 \pm 1.3^{*} & 44.0 \pm 12.0^{*} \\ \text { 5th } & 85 \pm 4^{*} & 3.3 \pm 0.13^{*} & 2.22 \pm 0.28^{*} & 3.43 \pm 0.41^{*} & 23.1 \pm 3.7^{*} & 89.3 \pm 1.5^{*} & 42.4 \pm 12.6^{*} \\ \text { 7th } & 80 \pm 5^{*} & 3.5 \pm 0.14^{*} & 2.27 \pm 0.33^{*} & 3.53 \pm 0.27^{*} & 26.5 \pm 4.4^{*} & 90.6 \pm 1.4^{*} & 43.8 \pm 11.4^{*} \\ \text { 9th } & 84 \pm 6^{*} & 3.4 \pm 0.13^{*} & 2.23 \pm 0.35^{*} & 3.45 \pm 0.30^{*} & 24.8 \pm 5.3^{*} & 89.7 \pm 1.5^{*} & 42.8 \pm 13.4^{*} \\ 11 \text { th } & 67 \pm 5 & 4.0 \pm 0.15 & 3.05 \pm 0.41 & 5.04 \pm 0.44 & 21.6 \pm 3.6 & 98.0 \pm 1.3 & 50.2 \pm 12.0 \\ 15 \text { th } & 51 \pm 5 & 4.2 \pm 0.13 & 3.15 \pm 0.45 & 5.30 \pm 0.41 & 44.3 \pm 3.5 & 108.5 \pm 1.2 & 52.6 \pm 10.5\end{array}$

\begin{tabular}{|c|c|c|c|c|c|c|c|}
\hline \multirow[b]{2}{*}{ 2nd } & \multicolumn{7}{|c|}{ Supplemented Vivarium Control Rats (SVCR), n=102 } \\
\hline & $53 \pm 6$ & $4.8 \pm 0.12$ & $3.57 \pm 0.43$ & $6.15 \pm 0.35$ & $42.7 \pm 4.4$ & $113.2 \pm 1.4$ & $54.7 \pm 11.4$ \\
\hline $3 \mathrm{rd}$ & $52 \pm 5$ & $4.7 \pm 0.15$ & $3.56 \pm 0.39$ & $6.13 \pm 0.43$ & $41.8 \pm 4.6$ & $113.3 \pm 1.5$ & $54.5 \pm 12.5$ \\
\hline 5 th & $54 \pm 5$ & $4.8 \pm 0.14$ & $3.54 \pm 0.43$ & $6.14 \pm 0.30$ & $42.7 \pm 5.3$ & $112.8 \pm 1.3$ & $54.9 \pm 13.2$ \\
\hline 7th & $53 \pm 4$ & $4.9 \pm 0.15$ & $3.57 \pm 0.40$ & $6.12 \pm 0.44$ & $41.6 \pm 4.5$ & $113.5 \pm 1.4$ & $54.6 \pm 12.0$ \\
\hline 9th & $52 \pm 6$ & $4.8 \pm 0.13$ & $3.58 \pm 0.36$ & $6.14 \pm 0.36$ & $42.5 \pm 4.0$ & $113.6 \pm 1.2$ & $54.7 \pm 13.4$ \\
\hline 11th & $53 \pm 4$ & $4.6 \pm 0.15$ & $3.53 \pm 0.47$ & $6.13 \pm 0.45$ & $41.7 \pm 6.0$ & $112.8 \pm 1.4$ & $54.5 \pm 12.0$ \\
\hline 15 th & $62 \pm 5$ & $4.5 \pm 0.13$ & $3.50 \pm 0.43$ & $6.12 \pm 0.42$ & $43.3 \pm 5.4$ & $113.6 \pm 1.3$ & $54.5 \pm 12.5$ \\
\hline \multicolumn{8}{|c|}{ Supplemented Hypokinetic Rats (SHKR), $n=102$} \\
\hline 2nd & $95 \pm 5^{*+}$ & $3.0 \pm 0.10^{*+}$ & $1.56 \pm 0.32 *$ & $2.42 \pm 0.45^{*+}$ & $18.0 \pm 3.6^{*^{+}}$ & $83.4 \pm 1.5^{*^{+}}$ & $40.7 \pm 13.4^{*^{+}}$ \\
\hline $3 \mathrm{rd}$ & $93 \pm 7^{*+}$ & $3.1 \pm 0.11^{*^{+}}$ & $1.58 \pm 0.35^{*}$ & $+2.44 \pm 0.31 *^{+}$ & $19.1 \pm 3.5^{*^{+}}$ & $83.8 \pm 1.3^{*^{+}}$ & $41.0 \pm 12.0^{*^{+}}$ \\
\hline 5 th & $98 \pm 4^{*+}$ & $2.9 \pm 0.13^{*+}$ & $1.55 \pm 0.45^{*+}$ & $+2.37 \pm 0.40 *^{+}$ & $16.3 \pm 4.0^{*^{+}}$ & $82.2 \pm 1.5^{*^{+}}$ & $39.3 \pm 10.5^{*^{+}}$ \\
\hline 7 th & $90 \pm 5^{*^{+}}$ & $3.0 \pm 0.12 *^{+}$ & $1.61 \pm 0.30^{*+}$ & $2.45 \pm 0.25^{*^{+}}$ & $18.4 \pm 3.4^{*^{+}}$ & $83.9 \pm 1.4^{*^{+}}$ & $40.8 \pm 11.5^{*^{+}}$ \\
\hline 9th & $96 \pm 6^{*^{+}}$ & $2.9 \pm 0.10^{*^{+}}$ & $1.57 \pm 0.41^{*+}$ & ${ }^{+} 2.40 \pm 0.32 *^{+}$ & $17.5 \pm 4.5^{*^{+}}$ & $82.7 \pm 1.5^{*^{+}}$ & $39.8 \pm 12.4^{*^{+}}$ \\
\hline 11th & $76 \pm 5$ & $4.4 \pm 0.11$ & $3.11 \pm 0.44$ & $5.17 \pm 0.43$ & $21.6 \pm 5.0$ & $98.3 \pm 1.3$ & $45.1 \pm 11.5$ \\
\hline 15 th & $57 \pm 5$ & $4.3 \pm 0.14$ & $3.40 \pm 0.38$ & $5.42 \pm 0.45$ & $41.0 \pm 4.4$ & $106.7 \pm 2.2$ & $51.0 \pm 13.3$ \\
\hline
\end{tabular}

